\title{
Considerations on the Protection of Historic Buildings in Wuhan: Starting from Tanhualin Protection
}

\author{
Yulu Zhuang ${ }^{1}$ \\ ${ }^{1}$ School of Civil Engineering and Architecture, Wuhan University of Technology, Wuhan, Hubei, 430070, China
}

\begin{abstract}
This paper takes the historical and cultural area of Tanhualin in Wuchang District as an example, from the historical construction present situation, the value of historical architecture, discusses three aspects of the historical building protection measures, and finally draws the conclusion: historical building protection needs to emphasize on protection, do repair old as before, to protect the culture at the same time also should pay attention to regain its vitality, achieve sustainable development, and carefully reconsider historical buildings in the present age, the function of space positioning.
\end{abstract}

\section{Introduction}

Wuchang Tanhualin historic district has five cultural elements: ancient city culture, religious culture, education culture, street culture and architectural culture. It is an important section for the exchange, collision and integration of Chinese and Western cultures in modern times. The rich historical buildings will still give the city a profound and long-term influence. Taking this area as an example, this paper discusses the thinking on the protection of historic buildings in Wuhan.

\section{Tanhualin general situation}

Tanhualin historic district is located in the northeast of the old town of Wuchang. It mainly starts from Zhongshan Road in the east to Desheng Bridge in the west, including Tanhualin, Gejia ying, Taiping Testuan, Madaomen, Sanyi Village, and Huayuan Hill and a strip of land within the two hills of Pangxiejia.

According to the regional division, the historical heritage protection work of Tanhualin area is mainly divided into three sections: the western section is positioned as a historical and cultural district. Starting from No. 81 Tanhualin Street and ending at Deshengqiao Street, the total length is $300 \mathrm{~m}$. The middle section is positioned as a cultural and leisure block, covering a total length of $280 \mathrm{~m}$ from Wuhan No. 14 Middle School to No. 81 Tanhualin Street. The eastern section is positioned as a cultural industry block, with a total length of $620 \mathrm{~m}$, starting from the entrance of Zhongshan Road and ending at the 14th Wuhan City [1].

\section{Status of Historic Buildings}

\subsection{Historic buildings are scattered}

The historical district of Tanhualin covers a wide area. The historical buildings are scattered in the district, with poor accessibility, lack of connection and cohesion between them, which can not heighten the historical atmosphere of the district as a whole.

The historic buildings that are not adjacent to the main street, due to poor accessibility, there is no continuous and attractive space to attract people, people rarely come. Garden Hill Catholic Church, for example, is a Romanesque basilica church built by Italian missionaries more than two hundred years ago. It is a magnificent and worthy place to visit. But it is located in a long narrow street, almost isolated from the main street, few people arrive.

\subsection{Most of the historic buildings are not properly preserved}

Due to the wide range of distribution of historical buildings, historical buildings lose their original features through the spontaneous reconstruction and construction of local residents and the replacement of homeowners under the changes of history. This leads to the phenomenon of mixed architectural layout and the decline of the whole historical atmosphere of the block. For example, the Swedish Diocese, is also the self-inhabited area of Tanhualin villagers [2]. In the decades after the founding of the People's Republic of China, more and more self-owned houses were built around the parishes and many historic buildings were confined to small alleys or courtyards, which affected the original appearance of the historic districts. On account of the excessive human

\footnotetext{
*Corresponding author: yuluzhuang@whut.edu.cn
} 
intervention in daily life and the lack of systematic protection, several historic buildings in the area have been damaged, even partially collapsed. So the rescue and protection work is imminent.

\subsection{The newly restored historic buildings do not continue the historical context}

The historic buildings on both sides of the main street are mainly used as shops after the facades are refurbished. Although their commercial value has been improved, they still face the dilemma of renovating old buildings like new ones and breaking the context. In addition, apart from a few commercial buildings are otago ancient buildings, most of the shops or archaize like new, or follow a typical town shop decoration form of literature and art. (See Figure 1)There is no different from shops in Gulangyu in Xiamen or Tianzifang in Shanghai.

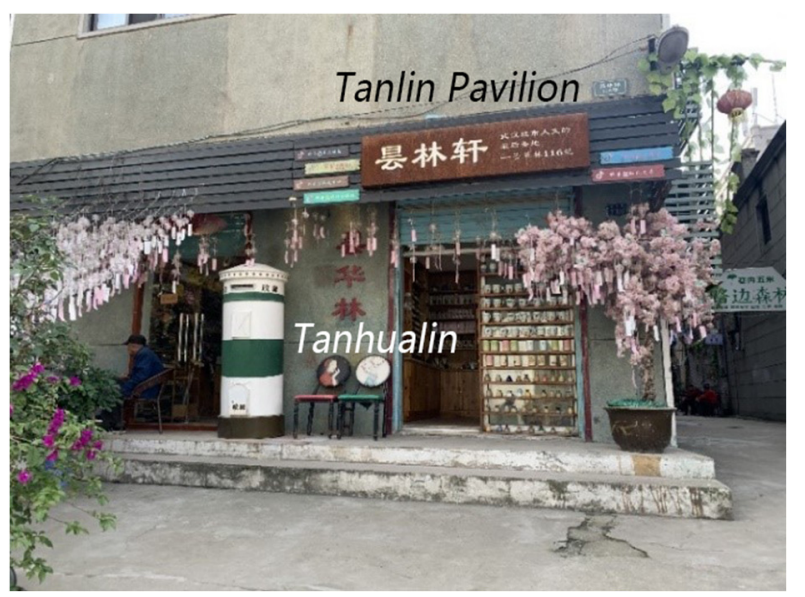

Fig. 1. The literary shop similar as which in Gulangyu and Tianzifang

\subsection{Historic buildings do not form an organic whole with their surroundings}

Historic buildings exist independently of their surroundings and are not affected by or influenced by the surrounding buildings. For example, in the main street of the middle section of Tanhualin, except for the historical buildings of Renji Hospital, it mainly presents a mixture of antique buildings (such as the historical and cultural exhibition hall of Tanhualin), modern residential buildings and scattered modern art shops (See Figure 2) [3]. Moving east to Wuhan No. 14 Middle School, the main street gradually becomes deserted, with fewer and fewer buildings open to the street, and the main street becomes a corridor for people.

While the historical buildings that have been greatly transformed and used as shops, there are also some historical buildings that have only been slightly reformed and strengthened. Most of them are dwellings and studios with high privacy, which seem to be out of place with the bustling main street. The doors are often closed and few people pay attention to them.

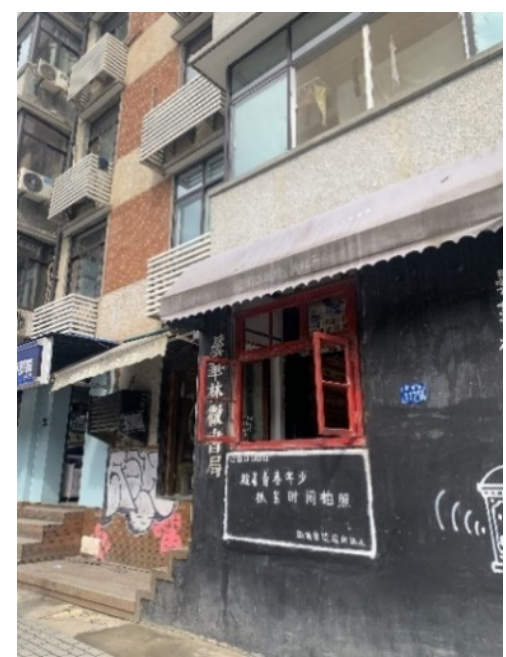

Fig. 2. Modern residential houses are mixed with art shops

\subsection{The buildings that remain on the block are no longer adequate for the modern lifestyle of the residents}

According to the investigation, the majority of people left in Tanhualin block are the elderly and children, as well as renters. Most of the residential houses are old houses that are forbidden to be demolished in the protected areas. By reason of their inability to meet the living environment of modern people, these old houses have suffered varying degrees of damage after artificial reconstruction, expansion and construction. Because of the high density of buildings in Tanhualin, it is difficult to add new social service facilities, which can only be solved through the surrounding communities and the traffic distance is too long. Due to serious material aging, the buildings and spaces in Tanhualin are no longer able to support the urban life today(See Figure 3).

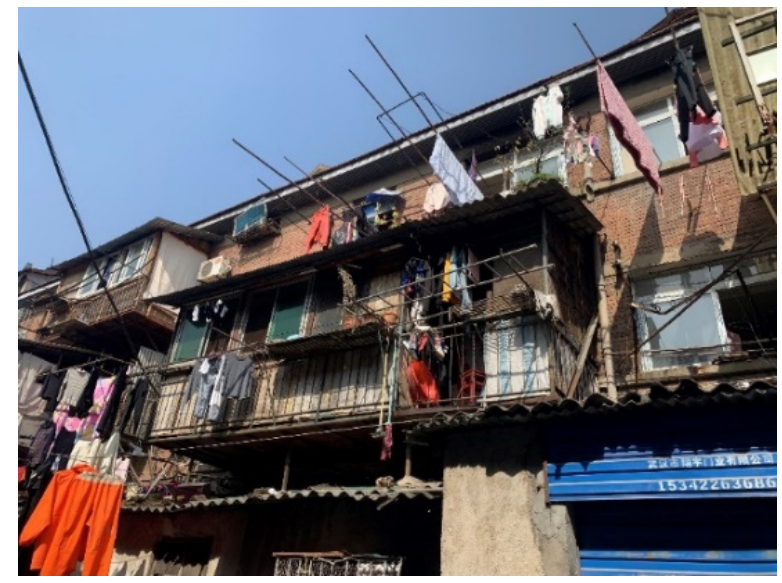

Fig. 3. Houses build by the residents themselves

\section{The value of historic buildings}

\subsection{Historic buildings are the material carriers of history}

Historic buildings bear witness to history and are the evidence of history. A series of historical events before and 
after the modern history play a leading role in the evolution of the architectural form of Wuhan. Discussing Wuhan's modern historical building cultural heritage protection achievements is also to discuss the value attitude of Wuhan's urban space in the construction process. As a well-preserved historical block in Wuchang, Tanhualin Historical and Cultural Area of Wuchang has witnessed the construction, development and protection process of Wuhan's modern historical buildings. Wuhan is the epitome of modern history, also known as the living Wuhan modern history book. It is of great theoretical value and practical significance for the protection and development of urban historic blocks. Therefore, the protection of Tanhualin is very important for the development of Wuhan.

\subsection{Historic buildings are the unique cultural symbols of a city}

Tanhualin historical area tells the story of the unique old Wuchang.Its existence gives Wuhan a unique charm and temperament. The protection of historical buildings is to protect the historical features of the city, to achieve the historical continuity of urban development and cultural diversity. Historic buildings are the cultural gene pool of a city, which records the information superimposing on space by time and interweaved with the urban living environment. By retaining and inheriting the urban memory, the historical buildings reveal the spirit and characteristics of a city.

Nowadays, more and more cities are faced with the problem of Same Imagines of the City. The similarity of the appearance of new buildings causes each city to lose its own characteristics. And the old city texture and historical buildings of each city become the valuable characteristics of each city. Just as people think of Beijing when they think of quadrangles, they think of Suzhou when they think of gardens.

\subsection{Historic buildings are a piece of historical jigsaw}

Collinlow wrote in his Collage City : European cities are like a collage, which combines elements of different ages such as the Middle Ages, Baroque and Renaissance together to form a city, so there will be no historical fault. We can walk through a street in Europe and browse the history of the development of the whole Europe. Historic buildings are like a piece of genetic information that remains to this day. If we remove all the historic buildings, then there will be a fault line in our history. We will not know what the land was like in the past.

\section{Conservation measures for historic buildings}

\subsection{The historical and cultural value of historic buildings should be enhanced during the preservation and renewal}

\subsubsection{Repair the old as the old should be achieved}

Excessive rectification should be avoided to make the historical buildings lose their social value, and the collective memory of Old Wuchang should be avoided to make fault. The influence of events in each period should be respected and retained.

\subsubsection{Rethink the functional positioning of historical buildings in the current era and space}

Put historical buildings into the whole district and even the city for consideration, so as to make them become the nodes with strong accessibility and vitality in the urban image. For example, the Renji Hospital in the main street of the middle section of Tanhualin is now an office building, which is not open to the public, and its value is not well utilized. Therefore, the main street nearby is extremely deserted. If it can be changed into a public tour building on the basis of establishing a complete set of protection rules, its value may be better explored.

\subsubsection{Historic buildings need to weaken their commercial value}

Avoid the phenomenon that the aboriginal people all move out due to excessive commercialization in the middle and late development of Tianzifang and Lijiang Ancient Town.

\subsection{Historic buildings and neighborhoods need to be renovated in parallel}

\subsubsection{Improve the street space}

Improve the street space so that it can lead people to the historic building and connect the historic building nodes.

\subsubsection{The cultural characteristics of blocks should reflect the value characteristics of historical buildings}

The cultural characteristics of blocks should reflect the value characteristics of historical buildings, and should not be occupied by a variety of monotonous art shops.

\subsection{Enhance the sustainability of historic buildings}

Both historic blocks and historic buildings cannot be displayed statically like some cultural relics on display, but should be developed dynamically. Some of the historic buildings in Tanhualin are idle or blocked. As time passes, the buildings are not taken care of, and the buildings will 
fall into disrepair, and the buildings will lose their vitality. For example, Shi Ying's former residence in Sanyi Village was tightly sealed by iron gates (See Figure 4), making it inaccessible to people. Such protection method could only temporarily protect its body, but could not protect its cultural spirit and historical connotation.

Both historic blocks and historic buildings cannot be displayed statically like some cultural relics on display, but should be developed dynamically. Some of the historic buildings in Tanhualin are idle or blocked. As time passes, the buildings are not taken care of, and the buildings will fall into disrepair, and the buildings will lose their vitality. For example, Shi Ying's former residence in Sanyi Village was tightly sealed by iron gates (See Figure 4), making it inaccessible to people. Such protection method could only temporarily protect its body, but could not protect its cultural spirit and historical connotation.

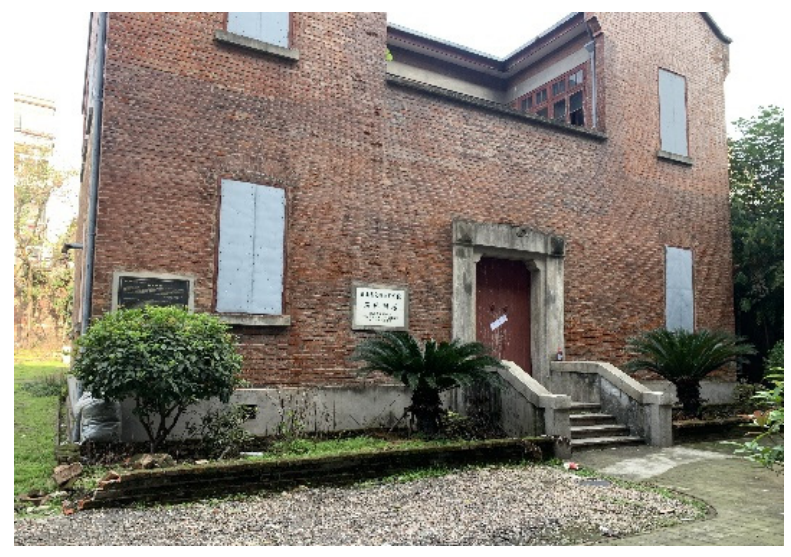

Fig. 4. The former residence of Shi Ying, which is off-limits to visitors

\subsection{Construction of government, community, unit and residents of the four-in-one protection mechanism}

With the development and evolution of Wuhan, Tanhualin historical and cultural area is not just a street or a few simple historical building nodes. It is a link of urban design in Wuhan urban renewal. Therefore, the protection of Wuhan's historical architectural and cultural heritage, including Tanhualin area, is not only the work of architects and planners, but also requires the cooperation of the government, investors and residents [5]. First, we need to attract investment and create employment opportunities for local residents. Second, it is necessary to build up the local residents' sense of responsibility and honor for the excellent historical buildings in the area, so that they can participate in the protection of historic buildings.

\section{Conclusion}

The value of historical buildings deposited through the baptism of time is not only the physical building itself, but also the social value contained in it. Historic architecture is the material carrier of history, the cultural symbol of a city, the memory inheritance of generations, and the perceptual cognition mixed with many vicissitudes of history. In Wuchang Tanhualin area historical and cultural area, for example, can be realized in the future and even all over the country engaged in historic buildings in Wuhan city protection work, the need to focus on protection, do repair the old as sweet, to avoid too many changes to its social value is lost, also avoided the rupture of the old residents' collective memory. At the same time, attention should be paid to enhancing the overall vitality of Tanhualin historical and cultural area to achieve the goal of sustainable development.

\section{References}

1. Mei Yn. (2013) Reflection on the Transformation of Historical and Cultural Districts Oriented by Cultural and Creative Industries : Taking Wuhan Tanhualin Historical and Cultural Districts as an Example. Huazhong Architecture, 12 : 158-160.

2. Hu Youbin, Li Haosheng. (2004) A Study on the Development and Development of Urban Historic Districts . Planners, 12 : 61-64.

3. Wang Xu, Zhang Yuanchun. (2010) Research on the protection and renewal of historic blocks -- a case study of Tanhualin block in Wuchang. Huazhong Architecture, 7 : 134-136.

4. Hu Rongrui, Hu Shaoxue. (2007) A study on the development and utilization of modern architectural heritage in Wuhan. Journal of Architecture, $05: 15$ 18.

5. Li Heping. (2003) Preservation and renovation methods of buildings in historic districts. City Planning Review, 04 : 52-56. 